\title{
Ilustrar el pasado precolonial andino: el caso de Jorge Zegarra Galdós
}

\section{Gabriel Ramón}

\section{(2) OpenEdition \\ 1 Journals}

Edición electrónica

URL: http://journals.openedition.org/bifea/10532

DOI: 10.4000/bifea.10532

ISSN: 2076-5827

Editor

Institut Français d'Études Andines

\section{Edición impresa}

Fecha de publicación: 1 abril 2019

Paginación: 57-81

ISSN: 0303-7495

\section{Referencia electrónica}

Gabriel Ramón, « Ilustrar el pasado precolonial andino: el caso de Jorge Zegarra Galdós », Bulletin de I'Institut français d'études andines [En línea], 48 (1) | 2019, Publicado el 08 abril 2019, consultado el 04 noviembre 2020. URL : http://journals.openedition.org/bifea/10532 ; DOI : https://doi.org/10.4000/ bifea. 10532

\section{(c) $(7)(9$}

Les contenus du Bulletin de l'Institut français d'études andines sont mis à disposition selon les termes de la licence Creative Commons Attribution - Pas d'Utilisation Commerciale - Pas de Modification 4.0 International. 


\title{
Ilustrar el pasado precolonial andino: el caso de Jorge Zegarra Galdós
}

\author{
Gabriel Ramón*
}

\section{Resumen}

La arqueología precolonial andina es un producto colectivo en el que participan diversos personajes desde la excavación hasta la publicación de los resultados. Dentro de este grupo se ha prestado muy poca atención a los personajes subalternos, como los ilustradores y los dactilógrafos (quienes escribían los diarios de campo). Este artículo presenta y discute la obra de un ilustrador y dactilógrafo extraordinario pero prácticamente desconocido, Jorge Zegarra. Este caso particular nos permitirá mostrar cómo se hacía arqueología precolonial en el Perú en un periodo muy poco estudiado (fines de los años 1940-inicios de los años 1960) y detenernos en una de las principales obras inéditas de Zegarra: sus «cuadernos de Huallamarca», pieza fundamental para la arqueología y la historia de la arqueología de Lima.

Palabras clave: Jorge Zegarra, ilustración arqueológica, historia de la arqueología, arqueología andina, Huallamarca

\section{Illustrer le passé précolonial andin : le cas de Jorge Zegarra Galdós}

L'archéologie précoloniale andine est un produit collectif dans lequel participent diverses personnages, depuis les fouilles jusqu'à la publication des résultats. Au sein de ce groupe, peu d'attention a été accordée aux personnages subalternes, tels que les illustrateurs et les preneurs de notes (qui ont tenu des carnets de terrain). Cet article présente et discute le travail d'un illustrateur et preneur de notes extraordinaire mais virtuellement inconnu, Jorge Zegarra. Ce cas particulier montre comment on a pratiqué l'archéologie précoloniale au Pérou pendant une période relativement peu étudiée (fin des

* Departamento de Humanidades, PUCP, Av. Universitaria 1801, San Miguel, Lima, Perú. E-mail: glramon@pucp.edu.pe 
années 1940 - début des années 1960), en se concentrant sur l'un des plus importants travaux inédits de Zegarra: ses « carnets de Huallamarca », fondamentaux pour comprendre l'archéologie et l'histoire de l'archéologie à Lima.

Mots-clés : Jorge Zegarra, illustration archéologique, histoire de l'archéologie, archéologie andine, Huallamarca

\title{
Illustrating the Andean precolonial past: the case of Jorge Zegarra Galdós
}

\begin{abstract}
Andean precolonial archeology is a collective product in which various characters participate from the excavation to the publication of the results. Within this group, little attention has been paid to the subaltern characters, such as illustrators and note-takers (who kept field diaries). This article presents and discusses the work of an extraordinary but virtually unknown illustrator and note-taker, Jorge Zegarra. This particular case examines how precolonial archaeology was done in Peru during a relatively unstudied period (late 1940s - early 1960s), focusing on one of Zegarra's most important unpublished works: his Huallamarca notebooks. These are fundamental for understanding the archaeology and history of archaeology in Lima.
\end{abstract}

Keywords: Jorge Zegarra, archaeological illustration, history of archaeology, Andean archaeology, Huallamarca

Salvo para un reducido círculo de arqueólogos peruanos, Jorge Zegarra Galdós (Puno 1923-Lima 1996) es un ilustre desconocido. Para quienes nos hemos cruzado con su extraordinaria obra gráfica y de registro arqueológico, esta situación solo se explica por la peculiar forma en que la arqueología se ha institucionalizado en el Perú. Así como la arqueología precolonial suele enfatizar las grandes figuras o la grandiosidad arcaica como parámetro narrativo, al tratar de la historia de la Arqueología se ha ponderado a los grandes personajes y se ha dejado de lado a aquellos menos visibles pero cruciales para entender esa disciplina. A estos personajes podríamos denominarlos subalternos, o más precisamente en casos como los de Luis Ccosi (1910-2003), Cirilo Huapaya (1911-1986), Toribio Mejía (1896-1983), Pedro Rojas (1913-2008) o Jorge Zegarra, subalternos extraordinarios, en la medida que, pese a no ocupar un lugar protagónico en el medio arqueológico, sobresalieron en sus campos (Emé Leyva, 2017; Melgar Vásquez, 2014; Téllez Cabrejos, 2003; Torres \& Williams, eds., 2010). Si bien en los últimos años la historia de la arqueología peruana se ha expandido notablemente (Gänger, 2014; Hernández, 2012; Tantaleán, 2014, Tantaleán \& Astuhuamán, eds., 2013, inter alia) el tema de los subalternos dentro de la disciplina sigue siendo el menos atendido'.

1 En este artículo se emplea la definición tradicional de subalterno como subordinado o «empleado de categoría inferior» (Diccionario de la Real Academia). Sobre la noción gramsciana de subalterno, diferente a la tradicional que empleamos, ver Modonesi, 2012. En una actividad como la Arqueología podemos identificar subalternos en varios niveles. Es decir, si bien Zegarra sería subalterno respecto a sus jefes en diversos proyectos arqueológicos, los obreros que participaron en las excavaciones a cargo de Zegarra pueden ser considerados sus subalternos. Significativamente en 
Para explicar la ausencia de personajes como Zegarra en la narrativa oficial sobre la historia de la arqueología peruana, también debemos considerar que carecemos de una política estatal coherente respecto a los archivos arqueológicos peruanos que permita un acceso fácil y completo a las colecciones de artefactos y especialmente a los documentos vinculados a ellos (e.g. listas de materiales, libretas de campo, reportes de excavación) (Ramón Joffré, 2017a: 558-560). Por esta limitación administrativa la historia de la arqueología peruana suele escribirse principalmente con base en documentos publicados o colecciones documentales depositadas en el extranjero, pero sin emplear material de archivos arqueológicos locales². Este enmarañado contexto ayuda a explicar la peculiar situación de obras como la de Jorge Zegarra. Abordarla permitirá también discutir esos problemas más amplios de la historia de la arqueología peruana a partir del caso concreto de un subalterno que destacó en la ilustración y el registro arqueológicos.

\section{LA ILUSTRACIÓN ARQUEOLÓGICA COMO GÉNERO LÍMITE}

Si tuviéramos que buscar un momento clave para explicar la génesis de lo que conocemos como ilustración arqueológica, este sería el siglo dieciocho, cuando aparece en América la figura del viajero ilustrado, particularmente del especialista dedicado a dibujar las nuevas especies animales y/o vegetales. En castellano el término «viajero ilustrado» tiene doble sentido: alude al movimiento intelectual, la ilustración, y revela también un rasgo típico del momento, la presencia de dibujantes como parte del equipo científico del viajero. No es casual que en el Perú los primeros dibujos de artefactos o sitios precoloniales pertenezcan precisamente a la segunda mitad del siglo dieciocho: las acuarelas sobre el norte del actual territorio peruano que acompañaban el texto perdido del obispo ilustrado Baltasar Martínez Compañón (Trever, 2012). Aunque en casos como el de Martínez Compañón desconocemos con precisión quiénes realizaron las ilustraciones; en general, el ilustrador podía ser alguien que acompañaba al viajero, un asistente local o el personaje mismo.

Si bien la relación entre este género más amplio (ilustrador) y la naciente disciplina arqueológica aún está siendo explorada, es en la segunda mitad del siglo diecinueve cuando la articulación entre ilustradores e investigadores del pasado precolonial andino se hace evidente (Echevarría López, 2012: 109-116; Emé Leyva, 2017: 21-30; Pillsbury, 2012; Rago, 2010: 23-26). Veamos tres ejemplos representativos de ese periodo. Primero, Antigüedades Peruanas (1851) de Mariano de Rivero y Johann Tschudi, que contiene un volumen especial para los dibujos de

la literatura peruana ya se ha explorado ficcionalmente el caso de un subalterno dentro del trabajo arqueológico, Candelario Navarro, vinculado a Julio C. Tello (1880-1947) (Martínez, 1977). Aquí nos centramos en el caso Zegarra que permite comenzar a vislumbrar esos niveles dentro de la disciplina arqueológica.

2 Al comentar el libro sobre historia de la Arqueología editado por Tantaleán y Astuhuamán, DíazAndreu (2013: 611) observa que solo dos de sus veintidós capítulos usan materiales de archivo. 
artefactos y sitios precoloniales. En el caso de los artefactos se trata de figuras aisladas, descontextualizadas. Segundo, la obra de Antonio Raimondi, quien, si bien no privilegiaba los restos precoloniales en sus investigaciones, hizo dibujos de artefactos y sitios precoloniales (Cárdenas Martín, 1993; Villacorta Ostolaza, 2012)3. Al inicio de su obra cumbre, Raimondi explica su interés por la ilustración según diversos campos. Así, al tratar de la botánica sostiene «Según mi modo de ver, un naturalista no es completo si no sabe dibujar con exactitud los objetos que somete al estudio» (1874: 103). Mientras tanto, al lidiar con la Arqueología se observa el impacto de las nuevas técnicas en sus sistemas de registro, ya que busca incorporar la fotografía:

En el curso de mis largos viajes, al hallarme en presencia de tantos preciosos monumentos históricos, experimentaba un verdadero sentimiento de no tener conmigo un aparato completo de fotografía, para sacar un dibujo exacto de todo lo que veía; y aunque hice la mayor parte de ellos [sic] dibujos con lápiz para mi álbum, sin embargo, ya por la escasez de tiempo que no me permitía dibujar todo lo que deseaba, ya por el temor de falsear alguna línea, nunca me hallaba satisfecho... (Raimondi, 1874: 109)

Este impacto de la fotografía marca también a otros contemporáneos suyos interesados en los restos precoloniales, como Ernst Middendorf o Ephraim Squier. Sin embargo, la ilustración no fue reemplazada por la fotografía, especialmente para lo que caracterizaría a la Arqueología como disciplina: la documentación de los contextos en detalle. Tercero, el trabajo de Wilhelm Reiss \& Alphons Stübel (1880-1887) sobre el sitio arqueológico de Ancón, al norte de Lima, implica un nivel distinto al de los trabajos previos, con detallados dibujos de los objetos, especialmente fardos funerarios debidamente localizados (Haas, 1986; Kaulicke, 1997: I). Los apuntes gráficos fueron tomados en Ancón por los autores y los detalles de los objetos recogidos (y llevados a Alemania) fueron completados en el gabinete. Para la reproducción de los tejidos se combinó fotografías y acuarelas (Carlson, 2000: 24). Si bien los autores no tenían una idea clara de la cronología, su nivel de registro es mucho más minucioso que el de sus antecesores. Estos tres ejemplos resumen una tendencia: la sofisticación técnica en la ilustración de restos precoloniales fue avanzando en paralelo con el perfeccionamiento de los sistemas de registro contextual.

El nacimiento oficial de la Arqueología académica en el Perú está marcado por las excavaciones de Max Uhle en Pachacamac en 1896. Por lo que sabemos, Uhle mismo realizó el registro gráfico en sus obras, especialmente los planos (Uhle, 1999). Ya en pleno siglo veinte, la figura del ilustrador como personaje asociado al arqueólogo es especialmente nítida en el caso de Julio Tello quien, por la magnitud de sus empresas de excavación, debió reclutar un equipo de jóvenes artistas para servir como asistentes en sus proyectos: Pablo Carrera, Rosa Carrión, Luis Ccosi, Evaristo Chumpitaz, Alejandro Gonzáles, Cirilo Huapaya, Hernán Ponce, Aquiles

3 El séptimo volumen de su obra especialmente dedicado a la etnología (con sus observaciones sobre restos precoloniales) se extravió. 
Ralli, Ricardo Robles, Pedro Rojas, Pedro Ulloa, entre otros (Echevarría López, 2012; Emé Leyva, 2017; Rago, 2010). La publicación periódica de las notas de campo de las excavaciones de Tello (los Cuadernos de Investigación del Archivo Tello) nos está ofreciendo un corpus único para observar la división del trabajo arqueológico, menos documentada en los casos anteriores. Lo primero que destaca es que, si bien un mismo subalterno podía ejercer varias funciones, es posible identificar cierta especialización. Por ejemplo, en el equipo de Tello había quienes se centraban en la ilustración, como Pedro Rojas, y quienes enfatizaban en el registro de los hallazgos arqueológicos, como Toribio Mejía ${ }^{4}$. Un segundo rasgo notable es la cantidad de trabajo realizado por los subalternos, pero cuán poco se les ha atribuido explícitamente, lo cual nos enfrenta al tema de la autoría 5 . Finalmente, un asunto complicado con algunas ilustraciones es icómo clasificarlas, cómo meros productos técnicos o como obras de arte? Pese a su gran calidad, estas obras, como las de Pedro Rojas, permanecen al límite entre las dos zonas (Torres \& Williams, eds., 2010). Este dilema clasificatorio respecto a las obras de los subalternos de Tello se vincula también a una cuestión social: sus autores no pertenecían a la élite limeña (Emé Leyva, 2017: 50-53). Por lo general eran migrantes de la sierra, con todo lo que ello implicaba en la capital peruana a mediados del siglo veinte: Ccosi era de Puno, Espejo y Rojas de Jauja, Mejía de Toro, Arequipa, entre otros. Jorge Zegarra y su obra se ubican precisamente en la situación límite descrita.

\section{DE PUNO A LIMA}

Los antepasados de Jorge Zegarra llegaron al Perú desde España en el siglo diecinueve ${ }^{6}$. Luego de un tiempo en la ciudad de Tacna se afincaron en Cuzco. Cuando joven, el tatarabuelo de Zegarra escapó a caballo hacia Puno con la que se convertiría en su esposa. Un abuelo de Zegarra incluso llegó a ser prefecto de Puno. En Puno nacieron los padres de Zegarra, Serafín Zegarra y Aurora Galdós, quienes tuvieron ocho hijos. Jorge fue el mayor. Zegarra realizó sus estudios en el colegio San Carlos de Puno, pero poco antes de concluirlos su padre tuvo problemas de presión arterial por lo que le recomendaron mudarse a la costa. En 1940 los Zegarra llegaron a Lima y luego de permanecer en casa de los padres de Aurora se fueron a Cañete, donde Serafín trabajó en la Caja de Depósitos y Consignaciones. Tras un año en Cañete, los Zegarra se mudaron a Huacho donde Serafín fue nombrado jefe de los almacenes fiscales de control de productos agrícolas que llegaban desde el norte del Perú hacia Lima. El grueso de la familia

4 Si los trabajos de Rojas frecuentemente alcanzan una factura que podríamos calificar de artística, los diseños de Mejía son más bien esquemáticos, cumplen con localizar los hallazgos. Compárense los dibujos de Mejía (2002a; 2002b) y los de Rojas (Torres \& Wiliams, eds., 2010). Es difícil encontrar gráficos de Mejía empleados como ilustraciones para publicaciones arqueológicas.

5 Víctor Pareces (com. pers.) editor de los Cuadernos de Investigación del Archivo Tello me contó que el tema de la autoría fue discutido por los editores a partir del volumen 6.

6 Esta sección (2), y las siguientes (3, 4), se basan en la entrevista realizada a Óscar Zegarra (junio de 2017) y el dossier que nos entregó, que incluye el currículo de su hermano (Zegarra, 1983). 
vivió en una casona de Huacho entre 1942 y 1965, pero los hijos mayores (Jorge, Rosa, Mario) se quedaron en casa de los abuelos maternos en el distrito de Breña7 . Jorge, quien «era muy rebelde», no se acostumbró a la rigidez de su abuelo y en 1941 ingresó al ejército al arma de caballería del cuartel 33, San Martín, Miraflores. Mientras estaba en el ejército, Zegarra concluyó sus estudios secundarios. Fue en esta época que sus dotes artísticas empezaron a destacar públicamente: hizo los bustos de caballos que se exhibían en la puerta del cuartel San Martín. En 1944 a causa de un accidente en la rodilla dejó el ejército.

Zegarra no cursó estudios superiores, fue autodidacta. Su hermano lo describe como alguien extraordinariamente talentoso: acuarelista, caricaturista, dibujante, escultor, maquetista y restaurador, «hacía cerámica», tocaba guitarra y rondín y cantaba8. Como arqueólogo se hizo en la práctica laboral. Realizó su formación profesional cuando la Arqueología como disciplina recién estaba consolidándose en el Perú: la parte más activa de su carrera va aproximadamente desde poco antes de la muerte de Tello hasta el surgimiento de la primera generación de arqueólogos profesionales de la Universidad Nacional Mayor de San Marcos a inicios de los años 1960. La trayectoria laboral de Zegarra tiene dos grandes fases. Una inicial caracterizada por el trabajo en conjunto con discípulos de Tello y otra de colaboración con el médico Arturo Jiménez Borja (1908-2000). Conviene revisarlas.

\section{DE AUXILIAR DE ESCULTURAS Y DIORAMAS A DIBUJANTE- DACTILÓGRAFO}

En 1945, al año siguiente de abandonar el ejército, Zegarra ingresa a trabajar en el Museo de Antropología y Arqueología de Pueblo Libre (hoy Museo Nacional de Arqueología, Antropología e Historia, en adelante museo). Sobre su ingreso al museo, Óscar Zegarra tiene dos hipótesis, no necesariamente excluyentes. La primera: Tello, como sucedió en otros casos, se enteró que existía un joven con talento para el dibujo y la escultura que podía ser útil para el museo y lo reclutó. La segunda — que sería también un indicador de la situación social de nuestro personaje- : los contactos de Serafín Zegarra hicieron posible que su hijo mayor llegara al museo. El museo pertenecía entonces al Ministerio de Educación, institución en la que Zegarra permanecerá hasta jubilarse en 1982 (fig. 1).

Durante su primer año en el museo, Zegarra hizo dibujos y se encargó de reparar cerámica en los talleres de esa institución. En Pachacamac, bajo la dirección de Tello, vigiló los trabajos de limpieza y restauración del Templo de la Luna, elaborando el diario de campo, con dibujos, esquemas, planos y fotografías.

7 En la calle Portugal, donde la pintora Tilsa Tsuchiya tendría su residencia y taller en la década de 1970.

8 Como observa María Eugenia Yllia, este talento múltiple coincidiría bien con la imagen del genio bohemia o walaychu (Poole, 1997: 177-178). 




Figura 1 - Jorge Zegarra con personal del Museo de Antropología y Arqueología, Pueblo Libre. Zegarra aparece en la primera fila encendiendo un cigarrillo, $1950^{9}$

(C) Archivo Óscar Zegarra

En 1946, también con Tello, exploró el complejo arqueológico Makatampu, realizando dibujos, trabajos escultóricos y reparando vasijas de cerámica en el museo10. Zegarra pertenece a la última generación de ilustradores y técnicos en arqueología que trabajaron con Tello. Esta breve relación fue descrita por Óscar Zegarra en los siguientes términos:

Julio [C.Tello], el sabio, estaba de director, y parece que vio los dibujos de este muchacho, lo que hacía... y se encandiló con él como se dice, y cuenta mi familia, me ha contado mi tía [Aida Galdós] que decidió enviarlo él, llevarlo a Ancón, justo Tello estaba haciendo los trabajos de las necrópolis de Ancón, y es más mi abuela me contaba 'oye no lo puedo creer, el mismo señor Tello viene en su, una camioneta, en una grandaza, en una camioneta grande' venía, con chofer, a recogerlo a mi hermano, muchachito para llevarlo hasta Ancón, se hizo pata, viejito el otro, ¿no?, o sea, le vio calidad, 'este muchacho tiene calidad'.

Entre 1945 y 1950 el Museo de Antropología y Arqueología llevó a cabo un gran proyecto de rescate en Ancón previo a la urbanización de la zona por parte de la compañía Miramar; se excavaron 1356 tumbas y 13240 objetos (Carrión Cachot,

9 Hay una foto más temprana de todo el equipo del museo, incluyendo a Tello (en Emé Leyva, 2017: 36), de 1945-1947 donde aparece Zegarra junto a Ccosi.

10 Makatampu se situaba hacia la cuadra 27 de la avenida Argentina, al límite entre El Callao y Lima (Tello, 1999). 
1951: 3)11. Entre 1946 y 1949 Zegarra participó de esas excavaciones elaborando diarios de campo con acuarelas, cortes estratigráficos, diagramas, dibujos, fotografías y planos (figs. 2, 3).

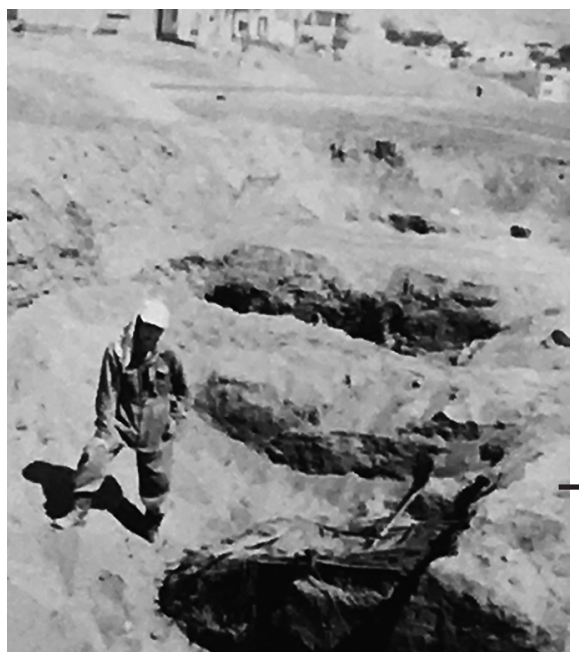

Figura 2 - Jorge Zegarra en las excavaciones de Ancón, 1948

(C) Archivo Óscar Zegarra

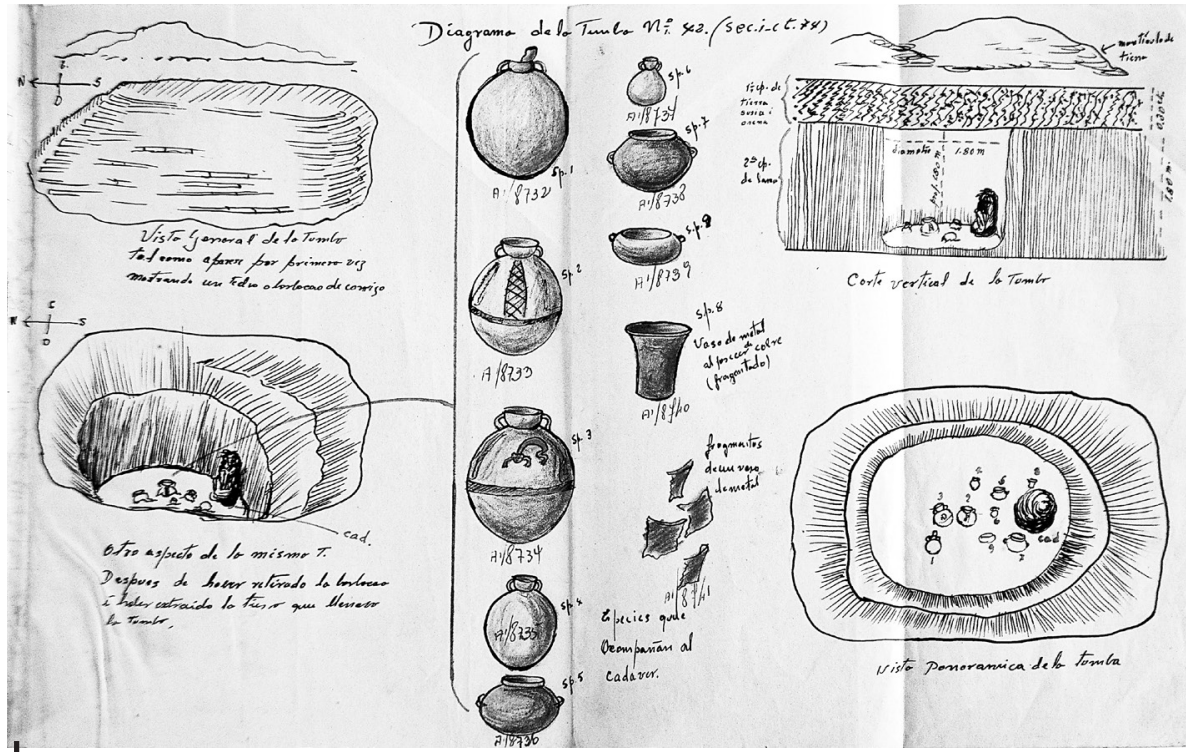

Figura 3 - Diagrama de la Tumba 42, Ancón 1946, por Jorge Zegarra

Diario de los Trabajos Arqueológicos en Ancón, Tomo IX, AT MNAAH

11 Sobre los trabajos realizados en Ancón ver Carrión Cachot, 1948; 1949a; 1949b; 1951; Haas, 1986: 22-24; Huapaya, 1948; Kaulicke, 1997: 15-16; Ravines Sánchez, 1977; 1981; Senado, 1953: 26, 48-50. Ravines Sánchez (1977: 327) tiene cifras distintas para las excavaciones de 1945 a 1950: 1570 tumbas y 14055 objetos. 
Para mostrar en detalle la diversidad de tareas realizadas por Zegarra en estos años iniciales de su carrera cabe presentar la información incluida en su informe anual de 1947 (Zegarra, 1947). Del 1 de enero al 18 de marzo, Zegarra se ocupó principalmente de pintar y retocar «réplicas de Sechín» y reconstruir tres tinajones de Ancón. Desde el 19 de marzo trabajó en Ancón

... Haciéndome cargo de la zona denominada $1^{\circ}$ ó Campamento $\mathrm{N}^{\circ} 3$. Durante mi permanencia en este Campamento hice el estudio simultáneo de 2 Secciones denominadas fajas: la primera zona alta y la Sección $1^{\circ}$, más la demolición del montículo "D" de basura. La labor externa de este campamento consistía en el estudio de las tumbas y la extracción de cadáveres y momias acompañados dichos estudios de planos, cortes, diagramas, fotografías, vistas panorámicas y dibujos especiales en láminas a la acuarela. El trabajo interno del campamento consistía en mantenimiento constante de limpieza y orden en lo que se refiere a las especies arqueológicas acumuladas y los enseres domésticos del campamento. Además, el movimiento de oficina que comprendía el tener al día los libros de registro de especies arqueológicas, el libro de caja, el libro de inventario de material de trabajo, los formularios de planillas de obreros, las listas de alimentación por duplicado, 1 folder con planos principales, cortes y diagramas (Zegarra, 1947).

Del 4 al 9 de junio de 1947 se suspendieron las labores para guardar duelo por el fallecimiento de Tello, director del museo. Seguidamente, Rebeca Carrión (1907-1960) asumió la dirección del museo y Mejía la subdirección: la primera coordinaba las actividades internas del museo, el segundo el trabajo de campo. Del 10 de junio al 15 de octubre, Zegarra vuelve a Ancón. De regreso en el museo, trabaja veinte días haciendo un plano de toda la zona arqueológica de «Ancón $1^{\circ}$ » y un diagrama del montículo «D» o «Sección $2^{\circ} »$. Del 10 de noviembre al 31 de diciembre vuelve a Ancón para encargarse de la «Sección $2^{\circ}$ » y luego de la «Zona $1^{\circ}$ ó Campamento $N^{\circ} 3$ 3. Zegarra firma este documento como «Aux. de Escultura y Dioramas» (Zegarra, 1947). Si bien el informe de 1947 muestra las actividades de Zegarra, no detalla sus relaciones con el resto del equipo, que sí aparecen en su informe de 1949. Conviene por ello reproducir la sección correspondiente a tres meses de ese año:

\section{FEBRERO.-}

Continúo en Ancón, hasta el 16 de Febrero, fecha en que fui traído nuevamente al Museo, comenzando a trabajar en él a partir del 17. Una de mis primeras tareas fue la reconstrucción gráfica de seis tipos diferentes de fardos funerarios procedentes de Ancón 1. Estos dibujos fueron utilizados para ilustrar un artículo de carácter arqueológico publicado en «El Comercio» por la Dra. Rebeca Carrión. Ayudé al Sr. Ccosi Salas en la confección de planos y esquemas arqueológicos de la Zona de las Necrópolis de Ancón 1.

MARZO.-

Durante todo este mes trabajé en el Taller de Dibujo $N^{\circ} 1$, dibujando a tinta china varias especies de cerámica y monolíticas de la Cultura 
Huaylas. Trabajé en compañía de Pablo Carrera confeccionando el Plano General de las Necrópolis de Ancón 1. Además, hicimos en dicho plano la representación gráfica de las Tumbas estudiadas.

\section{ABRIL.-}

Durante el mes de Abril trabajé nuevamente en las Necrópolis de Ancón como Dibujante-Dactilógrafo, bajo la jefatura del Sr. Luis Ccosi Salas. Durante mi permanencia en esta región hice varios planos a escala y por duplicado de las zonas de estudio. Además, láminas a lápiz y a la acuarela. También ilustré detalladamente con vistas panorámicas, croquis y cortes, dos volúmenes de 400 hojas cada uno, o sean [sic] los Diarios del Campamento № 3 de Ancón, Tomos XXIX y XXX (Zegarra, 1949).

Este informe de 1949 permite observar cómo el joven puneño participaba en la producción del conocimiento arqueológico: trabajaba algunos periodos en el campo y otros en el museo, principalmente como ilustrador, o como él mismo señalaba «Dibujante-Dactilógrafo». Nos enteramos además de su interacción con los otros miembros del equipo: Zegarra menciona haber trabajado con Pablo Carrera (marzo), bajo la dirección de Ccosi (febrero, abril, mayo) y del jefe de exploraciones, Julio Espejo (enero, mayo), haber tenido como dactilógrafo al estudiante de letras Teófilo Garay «destacado por la Dirección del Museo para presenciar estudios arqueológicos por vía de experimentación» (mayo), haber recibido una comisión de trabajo del subdirector del museo (agosto) y haber tenido como auxiliar a Francisco Iriarte (junio). Con algunos de los miembros de su equipo Zegarra estableció una estrecha relación, como el escultor y maquetista Ccosi y el entonces estudiante Iriarte.

Los diarios de campo brindan más información de cómo podían variar los roles en las excavaciones. Así, por ejemplo, en la carátula del tomo XXVII del Diario de Trabajos Arqueológicos en Ancón (31 enero-14 febrero 1949) Julio Espejo aparece como informante (quien dictaba lo que debía registrarse en el cuaderno), Zegarra figura como dibujante, y otros tres (Teófilo Garay, Alejandro Guanilo, Carlos Villafuerte) como dactilógrafos. Sin embargo, en las notas a la excavación de la tumba 680 se informa:

Actuando como informante i dactilógrafo i dibujante Jorge Zegarra, y como ayudantes encargados del empaquetado i traslado de las especies, los obreros Guanilo i Martínez12.

En general, los numerosos cuadernos de campo de Ancón revelan a Zegarra trabajando en un equipo que tiene directivas generadas durante el periodo de formación con Tello, que el joven dibujante va asimilando. Finalmente, el artículo de Carrión al que alude Zegarra en su informe de 1949 apareció en El Comercio (Carrión Cachot, 1949b) incluyendo su dibujo sobre tipos de fardos de Ancón.

12 Museo Nacional de Arqueología Antropología e Historia (en adelante MNAAH), Archivo Tello, AT051-2001: 84 . 
Aunque la autoría de Zegarra no es consignada, se trata de su primera ilustración en un medio público (fig. 4).

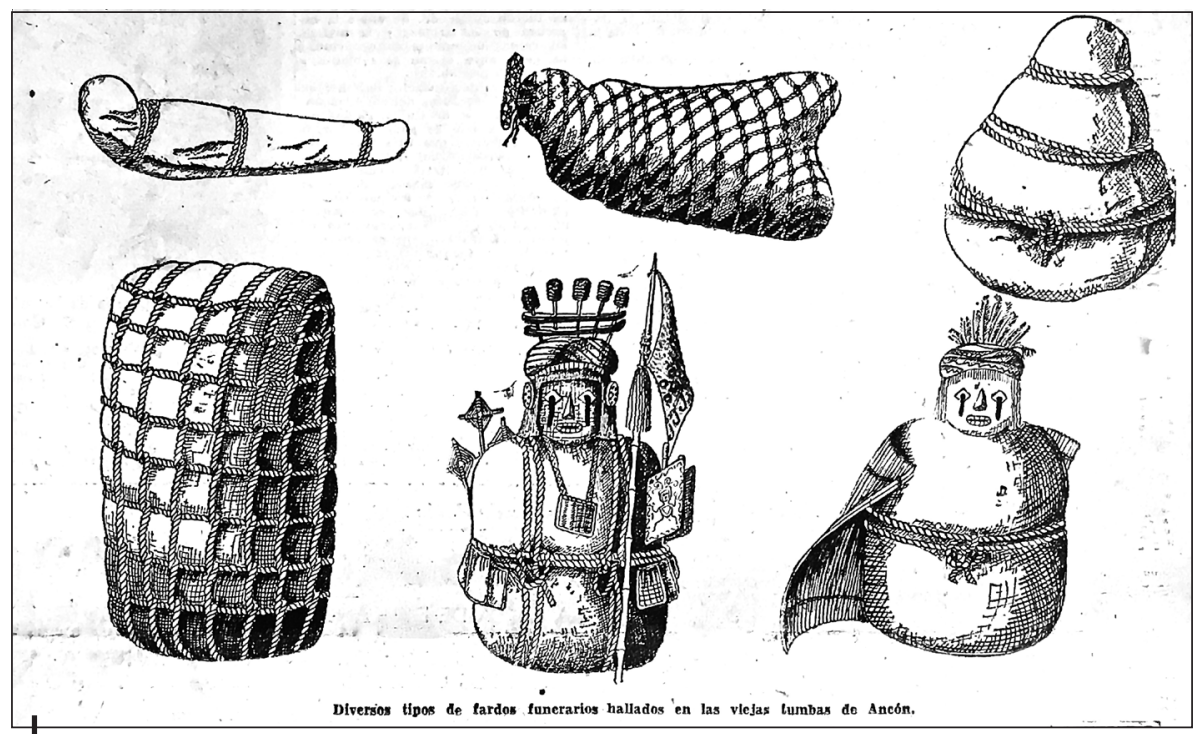

Figura 4 - Dibujo de Zegarra en el artículo de Rebeca Carrión (1949b: 3)

Entre 1950 y 1956, Zegarra siguió participando en las excavaciones realizadas por el museo en Ancón, en las que solo entre 1950 y 1953 se registraron 879 tumbas y 11090 objetos (Ravines Sánchez, 1977: 328). También en esos años Zegarra realiza exploraciones en los sitios arqueológicos de Juliana, distrito de Miraflores, y «de la universidad», distrito de Jesús María, elaborando un «diario de campo con sus respectivas ilustraciones» 13 . Paralelamente, en el museo, Zegarra continuó clasificando cerámica y haciendo «catalogación ilustrada» de cerámica «Chimú, Mochica y Tallán», dibujos, acuarelas y óleos de tejidos paracas. Hizo trabajos de escultura y reparación de cerámica con Ccosi con quien además colaboró «en la realización de la maqueta de Machu Picchu».

\section{DE DIBUJANTE-DACTILÓGRAFO A TÉCNICO EN ARQUEOLOGÍA Y DIBUJO}

A fines de los años 1950 Zegarra ya es un dibujante y dactilógrafo curtido en Ancón y su radio de acción va a ampliarse. Zegarra comienza a trabajar bajo la dirección de Arturo Jiménez Borja, con base en el sitio de Puruchuco, distrito de Ate Vitarte, en un equipo cuyos miembros tenían menos experiencia de campo

13 La «huaca de la universidad» estuvo situada en un terreno de la Universidad Nacional Mayor de San Marcos, donde, entre 1951 y 1958, se construyó el Hospital del Empleado (Tello, 1999 [1929]). 
que los discípulos de Tello con los que se había formado. En 1957 explora y excava los sitios de Catalina Huanca y Huaquerones, ambos en Ate Vitarte, elaborando un «diario de campo con sus respectivas ilustraciones». Realiza dibujos y «otras labores de carácter arqueológico» en Puruchuco (El Comercio, 1958a) (ver foto de Iriarte, Jiménez Borja y Zegarra en Puruchuco en Villacorta, 2004: 62) En 1957 1958 lleva a cabo labores de limpieza y restauración del sitio arqueológico de San Juan de Pariachi, próximo a Puruchuco, elaborando un «diario de campo ilustrado». Paralelamente, en Puruchuco hace dibujos en tinta china y «otras labores arqueológicas».

En marzo de 1958, realiza labores de limpieza y restauración del sitio Pan de Azúcar (hoy Huallamarca), distrito de San Isidro, excavando contextos funerarios y elaborando el «diario de campo con sus respectivas ilustraciones». Asimismo, participa en la organización de una exposición de los materiales excavados en Huallamarca en la galería del Banco Continental (Jiménez Borja, 1958; El Comercio, 1958b; El Comercio, 1958c; La Tribuna). Estos trabajos en Huallamarca fueron un hito en la carrera de Zegarra; gracias a ellos adquirió cierta notoriedad pública como arqueólogo, especialmente por su labor de rescate de un sitio amenazado por las compañías urbanizadoras. Si bien la historia oficial destaca, con justicia, la figura de Jiménez Borja en la salvación de Huallamarca (Villacorta, 2004: 76-77), cabe recordar que el trabajo cotidiano y los minuciosos cuadernos de campo de esa temporada fueron obra exclusiva de Zegarra. Como el propio Jiménez Borja (1958) reconoció:

Los trabajos de campo han estado a cargo de Jorge Zegarra y el público podrá apreciar y hacer justicia de su extraordinaria competencia (figs. 5, 6).



Figura 5 - Jorge Zegarra en Huallamarca, 1958

(C) Archivo Óscar Zegarra 




Figura 6 - Exposición «Huallamarca, primeros pobladores de San Isidro», 1958

(C) Archivo Óscar Zegarra
En 1960 Zegarra realiza trabajos de limpieza y restauración en el sitio de la Fortaleza de Paramonga, provincia de Barranca, Lima, incluyendo la exploración y la excavación de diversos sitios arqueológicos. Como de costumbre, todo su trabajo fue registrado en un «diario de campo con ilustraciones» (fig. 7). En 1961 Zegarra elabora dibujos a tinta china y «otros trabajos arqueológicos» en Puruchuco y prosigue con la restauración de San Juan de Pariachi con Carlos Guzmán e Iriarte (Buse de la Guerra, 1962: 29). Vuelve a hacer excavaciones de rescate en Ancón elaborando un «diario de campo con sus ilustraciones» (Buse de la Guerra, 1962: 30; Haas, 1986: 26). También en 1961 explora y excava diversos sitios arqueológicos del valle de Chancay, acompañado por José Casafranca e Iriarte, bajo la dirección de Hans Horkheimer de la Misión Arqueológica Alemana (Horkheimer, 1962). Entre 1962 y 1964 Zegarra retorna a Pachacamac, donde hace trabajos de limpieza y restauración en la zona de Mamacona, Pirámide «J.B.», Templo del Sol y de la Luna elaborando un «diario de campo ilustrado» (Buse de la Guerra, 1962: 30-31; Expreso, 1964)14. Además de llevar a cabo labores administrativas en Pachacamac, realiza trabajos arqueológicos en Puruchuco.

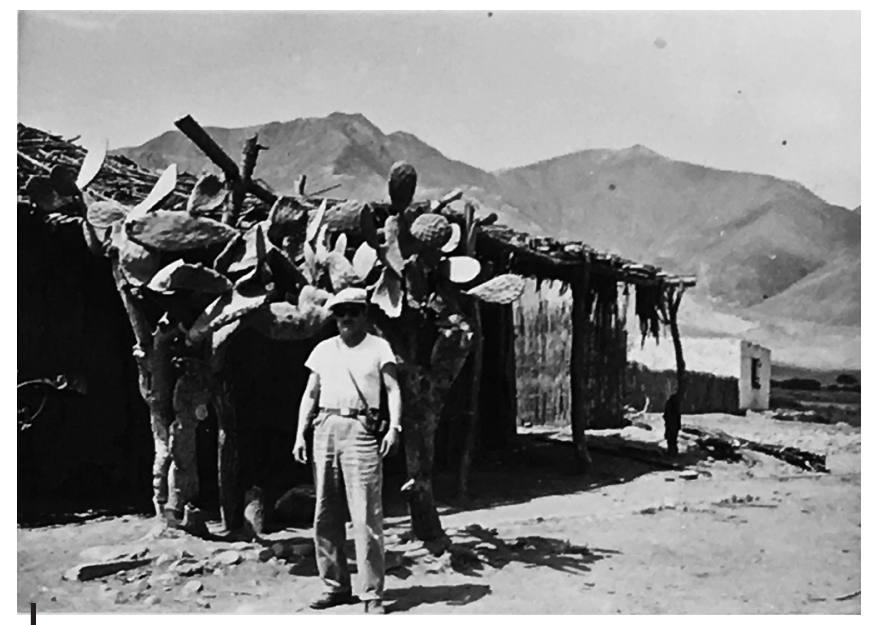

Figura 7 - Jorge Zegarra en Paramonga, 1960

(C) Archivo Óscar Zegarra

14 Actualmente en el Museo de Sitio de Pachacamac hay cuatro cuadernos de campo vinculados a las fechas aquí estudiadas. Tres de ellos son, con certeza, de Zegarra (1961-1962; 1962-1963; 1963 1964). En el caso del cuaderno más temprano (1957-1959), su autoría no corresponde a Zegarra si consideramos datos internos del documento. 
En enero de 1963 Zegarra es oficialmente reconocido como «técnico adscrito» al Patronato Nacional de Arqueología (L.E. Valcárcel firma el documento). Pese a este espaldarazo oficial, desde entonces sus actividades arqueológicas disminuyen (ver Zegarra, 1983). Entre 1964 y 1969 trabaja en el sitio de Chan Chan, Trujillo, bajo la dirección de Iriarte, como auxiliar de campo en la limpieza y restauración del sitio, elaborando dibujos, acuarelas, témperas, planos y dioramas (Buse de la Guerra, 1965: 126-127, 371-379). En 1968 excava contextos moche en Huanchaco, Trujillo (La Industria, 1968). Entre 1970 y 1971 realiza labores de limpieza en el sitio de Santa Catalina, distrito de La Victoria, elaborando dibujos, dioramas y planos (Ghersi \& Zegarra, 1971-1972; El Comercio, 1971; La Prensa, 1971) (fig. 8). Entre 1980 y 1982 trabaja en Chavín de Huántar, Ancash, como auxiliar de campo de Iriarte y de Federico Kauffmann, elaborando cortes, diagramas y planos esquemáticos. Al parecer Iriarte llevó a Zegarra a la Universidad Nacional Federico Villarreal donde realizó algunas labores. Luego de jubilarse del museo, Zegarra mantuvo sus intereses artísticos dedicándose a actividades como la elaboración de réplicas de piezas arqueológicas o a la instalación de un taller de cerámica para uno de sus hijos.



Figura 8 - «Huaca Sta. Catalina. Restauración del Templete. Diciembre 1971» (texto al reverso de la foto)

(C) Archivo Óscar Zegarra

\section{LOS CUADERNOS DE HUALLAMARCA}

Se sabe que Zegarra dio dos charlas públicas, ambas en 1968, en Trujillo: «Excavaciones Técnicas en Arqueología» en el Centro Cultural Peruano Norteamericano y otra en el Instituto Liberteño de Arqueología15. Sin embargo, no se conocen publicaciones suyas: sus cuadernos de campo y reportes están inéditos. Si bien su obra es desconocida para el público, hay un caso excepcional: sus cuadernos de Huallamarca.

Entre febrero y noviembre de 1958 y en agosto de 1960 el sitio fue excavado por un equipo principalmente compuesto por empleados de la municipalidad de San Isidro y soldados del cuartel San Martín (donde Zegarra había servido en la primera mitad de la década de 1940). La intención de la excavación era habilitar el sitio como monumento arqueológico y «recuperar su forma original» para poder exhibirlo. La coordinación general fue de Jiménez Borja. Luego de un breve periodo a cargo de Iriarte las excavaciones fueron realizadas por Zegarra a partir del 14 de marzo. Se excavaron 52 contextos funerarios, aunque solo 51

15 Observación basada en dos recortes de periódico sin identificación de fuente en posesión de Óscar Zegarra. 
fueron adecuadamente registrados por Zegarra y solo 48 cuentan con un dibujo general y la información sobre la relación entre las piezas. El inventario incluye unas 1325 entradas.

Los cuadernos de Huallamarca han tenido una sinuosa fortuna crítica que conviene revisar esquemáticamente. La primera referencia aparece en el libro de arqueología ficcional de los escritores y exploradores franceses Roger y Simone Waisbard (1960) (ver Vescelius, 1966). Este libro prácticamente gira en torno a las excavaciones en Huallamarca. Incluye múltiples referencias a Zegarra (l'éminent dessinateur) (Waisbard \& Waisbard, 1960: 44, 61, 62, 98, 100, 128) y reproduce 4 de sus dibujos (debidamente reconocidos), 3 de los cuales también aparecen en su diario de campo (cámara funeraria 8, tumba 16, tumba 25).

Casi cuatro décadas más tarde, Martín Mac Kay Fulle (1997: 248) hace una breve alusión a los cuadernos en un artículo sobre figurinas precoloniales del valle del Rímac ${ }^{16}$. Siete años después, en un libro en homenaje a Jiménez Borja, hay una referencia más extensa a los cuadernos de Zegarra, incluyendo la reproducción de seis de sus dibujos. Daniel Guerrero (2004: 157) observa que los cuadernos «han permanecido desconocidos hasta la actualidad a pesar de su importancia y vigencia para la discusión de la problemática de la arqueología de esta región [valle bajo del Rímac]». Sin embargo, no menciona al autor de los cuadernos, pese a citarlo en la bibliografía. Luis Felipe Villacorta (2009: 75) alude rápidamente a los cuadernos en un texto sobre Jiménez Borja. En general, los autores que más han usado los cuadernos de Zegarra sobre Huallamarca en sus publicaciones han sido Camilo Dolorier \& Lyda Casas (2008; 2009; 2014; 2016). Incluso, la tesis de licenciatura de Dolorier (2013) es una interpretación del sitio de Huallamarca con base en los cuadernos de campo de Zegarra. Cerrando el círculo, una de las alusiones más recientes a los cuadernos es una breve nota reconociendo la calidad de los dibujos de Zegarra por una escritora canadiense especializada en arqueología que se cruzó con ellos en Puruchuco (Pringle, 2012)17.

Pese a todo este interés, los cuadernos no han sido descritos como fuentes documentales, por lo que cabe presentarlos. En total, los cuadernos de Zegarra vinculados a Huallamarca son siete: cinco de su autoría (1958a; 1958b; 1958c; 1958d; 1960) y dos, más breves, en los que figuran dos autores (Zegarra \& Iriarte, 1958a; 1958b). Los dos primeros volúmenes (Zegarra, 1958a; 1958b) constituyen los volúmenes centrales (piezas 41-1168) (figs. 9, 10a, 10b, 11a, 11b, 12a, 12b), registrando las actividades de excavación del 14 de marzo al 16 de octubre de 1958. El tercero (Zegarra, 1958c) está principalmente dedicado a los trabajos de restauración de San Juan de Pariachi, pero del 17 al 20 de octubre se registran

16 Martin Mac Kay (com. pers.) supo de los cuadernos de Zegarra en el seminario II de la especialidad de Arqueología de la Pontificia Universidad Católica del Perú dictado por Peter Kaulicke en 1997.

17 Además de elaborar un reporte de investigación sobre los cuadernos de Zegarra (Ramón, 2003), los he utilizado en dos publicaciones (Ramón, 2014: 102-103; Ramón Joffré, 2017b: 290-291). Sobre otros documentos de Zegarra, he identificado la reproducción de un dibujo de su cuaderno de Pachacamac 1961-1962 (Franco Jordán, 2004: 483, fig.16; Ángeles Falcón, 2011: 22) y menciones al reporte de Ghersi \& Zegarra, 1971-1972 (Cornejo Guerrero, 1998: 193, 196,198). 


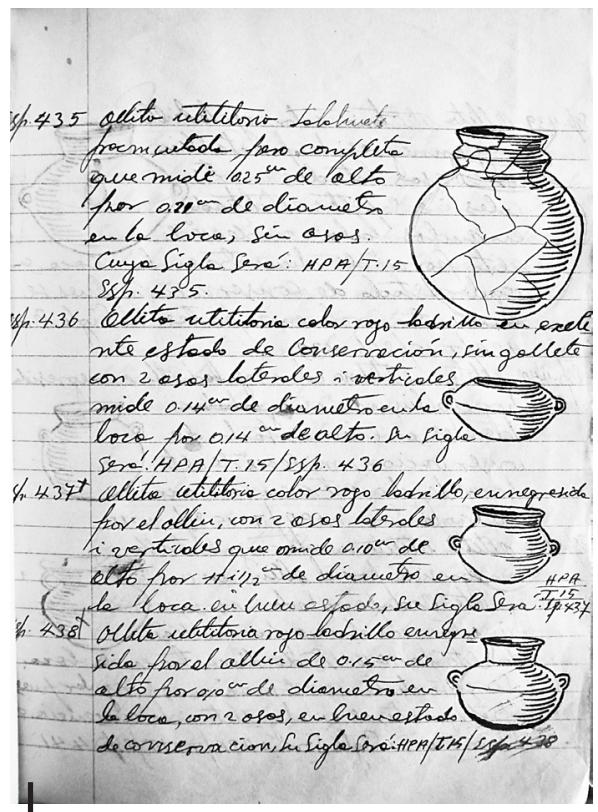

Figura 9 - Página de descripción de materiales del Tomo I del cuaderno de campo de Huallamarca

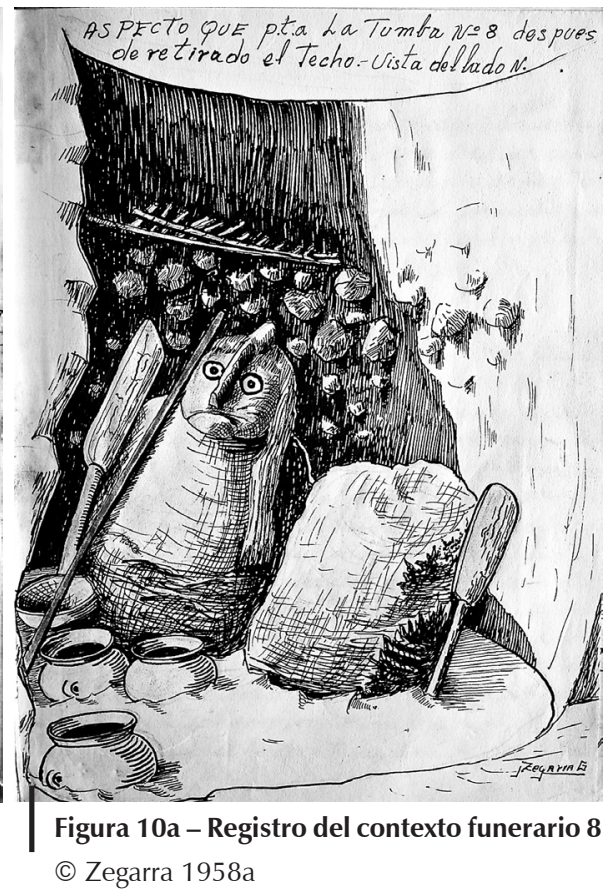

(C) Zegarra 1958a

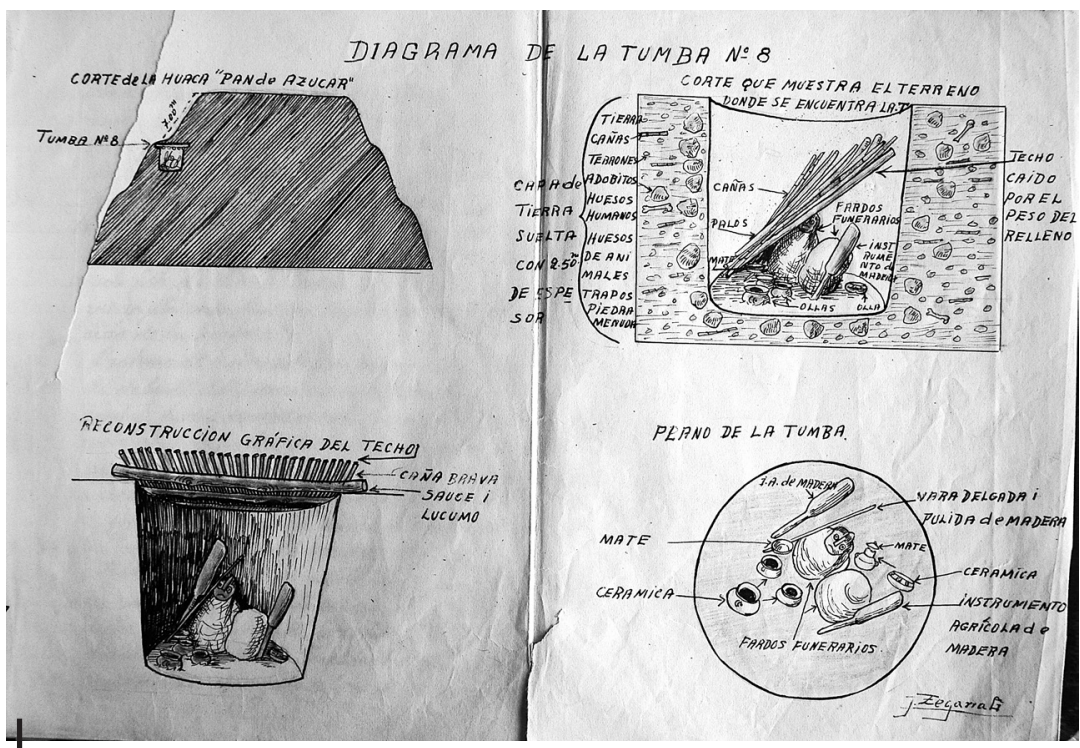

Figura 10b - Registro del contexto funerario 8: vista lateral y diagrama

(C) Zegarra 1958a 
Ilustrar el pasado precolonial andino: el caso de Jorge Zegarra Galdós


Figura 11b - Registro del contexto funerario 11: vista lateral y diagrama

(C) Zegarra 1958a 


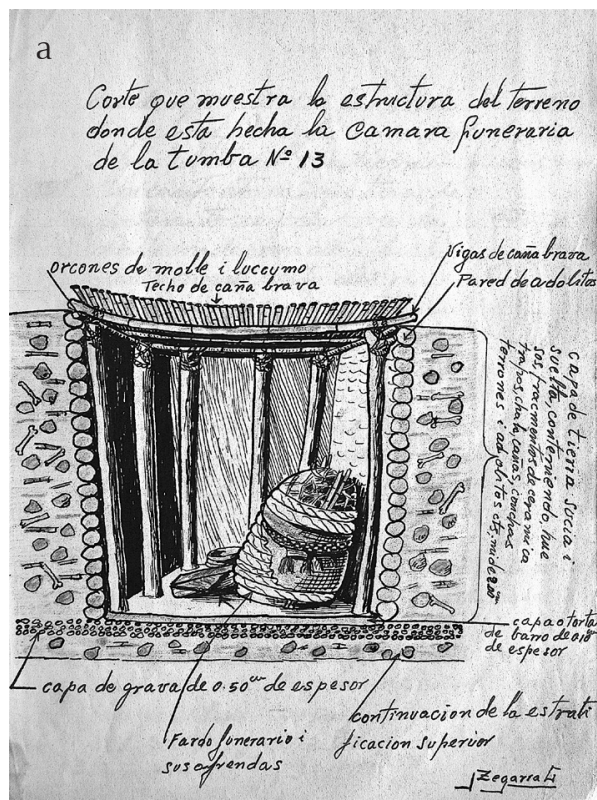

b FABDO FUNERARIO DELA TUMBAN NO13.

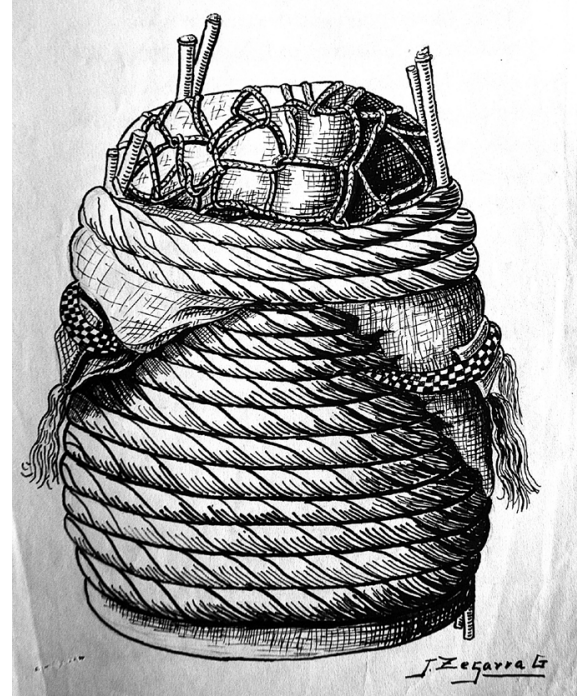

Figuras 12a, 12b - Registro del contexto funerario 13: vista y detalle

Este ejemplar posteriormente fue desenfardelado en público (La Prensa, 1958)

(C) Zegarra, 1958a

ejemplares de Huallamarca (1169-1207). El quinto tomo (Zegarra, 1960) contiene el registro faltante de los materiales (1208-1325) (fig. 13). El primero de los textos en coautoría (Zegarra \& Iriarte, 1958a) registra ejemplares de Huallamarca (1-45). El segundo en coautoría (Zegarra \& Iriarte, 1958b) es la copia mecanografiada de 1958a y parcialmente de Zegarra \& Iriarte 1958a. Zegarra alude a un cuaderno específico para los desenfardelamientos que falta localizar (anotaciones del 1 de setiembre de 1958, Zegarra, 1958c).

Si bien los cuadernos de Zegarra sobre Huallamarca requieren un análisis más detallado, podemos indicar que son importantes por, al menos, cuatro razones. Primera, son herramientas para reconstruir contextos arqueológicos de un sitio clave para la arqueología de Lima (Guerrero, 2004; Dolorier, 2013; inter alia). Segunda, sirven como documento histórico sobre los métodos de registro en los años 1950 y sobre lo que pasaba al momento de su redacción: incluyen notas sobre la historia de San Isidro, más allá de las excavaciones (Ramón Joffré, 2014: 102-103). Tercera, pese a que han sido asumidos como fuentes descriptivas, incluyen ejercicios interpretativos sobre las funciones de los objetos, basados en los conocimientos etnográficos de Zegarra (Ramón Joffré, 2017b: 290291), probablemente vinculados a su infancia y adolescencia en Puno. Cuarta, por la calidad de sus ilustraciones que permiten discutir los límites entre arte y arqueología. En suma, pese a ser los cuadernos más citados de Zegarra tienen aún mucho material que brindar a los investigadores. ¿Qué pasaría si se conociera mejor el resto de su producción y la de otros autores en situación semejante? 


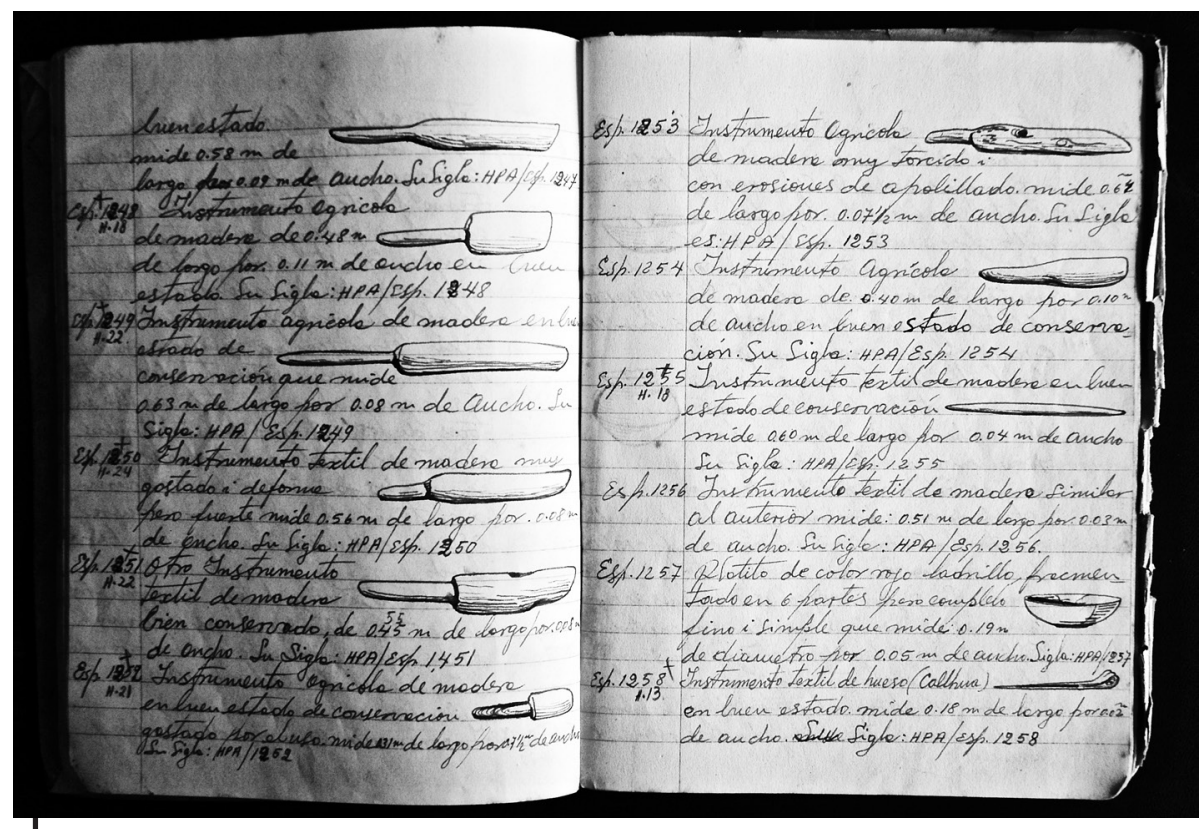

Figura 13 - Página de descripción de materiales del Tomo $V$ del cuaderno de campo de Huallamarca

(C) Zegarra 1960

\section{CIERRE Y PERSPECTIVAS}

El creciente interés de los arqueólogos por incorporar a los subalternos (sensu Gramsci) en la narrativa del pasado precolonial andino seguramente permitirá una lectura más completa del mismo. Sin embargo, no debemos dejar de lado la intervención de los subalternos (según la definición tradicional, al menos) en la producción de la Arqueología como disciplina. Zegarra forma parte de este grupo de personajes que podemos denominar subalternos, aludiendo a su posición dentro de la división del trabajo arqueológico: produjeron cuadernos de campo y reportes, pero raramente publicaron. Estos personajes básicamente han desaparecido de la literatura, opacados por las grandes figuras. Sin embargo, debemos considerarlos tanto para entender cómo se producía el conocimiento arqueológico en el pasado (historia de la Arqueología) como para poder producir conocimiento arqueológico en el presente, usando adecuadamente los documentos elaborados por ellos (Arqueología).

La información presentada permite situar preliminarmente a nuestro personaje y pensar en su propuesta de lectura del pasado precolonial. Si bien Zegarra comparte algunos rasgos generales con la mayoría de los discípulos de Tello (i.e. origen fuera de Lima, formación principalmente técnica, producción de cuadernos de campo pero no de publicaciones académicas), a la vez presenta atributos que lo distinguen. Por ejemplo, en su obra no se percibe claramente 
el denominado «indigenismo telúrico-arqueológico» (Emé Leyva, 2017: 9-20) evidente en personajes como Pablo Carrera, Luis Ccosi, Pedro Rojas o Toribio Mejía. Esta diferencia se podría explicar por varias razones, una de ellas sería el poco tiempo que Zegarra pasó bajo el mando de Tello, por ser mucho más joven que el resto del equipo. Ello también ayudaría a entender su ausencia en colectivos artísticos como el grupo Waman Poma (1943-1949) donde participaron varios de los discípulos de Tello (Rago, 2010: 27-30). Esta interpretación es solo hipotética hasta que la producción escrita y gráfica de Zegarra sea explorada con mayor detenimiento. El estudio sistemático y comparativo de los cuadernos de campo de Zegarra en relación con los textos producidos por arqueólogos «profesionales» de su época (o inmediatamente anteriores y posteriores) nos permitirá aproximarnos a las relaciones entre trabajo arqueológico «empírico» (i.e. excavaciones, clasificación de material en gabinete) y propuestas narrativas oficiales y/o teóricas sobre el pasado precolonial. Por ejemplo, ¿qué tipo de periodificación manejaba Zegarra?, ¿qué criterios empleaba para clasificar el material cerámico? ¿cómo el trabajo de personajes subalternos, como Zegarra, era incorporado (o no) en la narración del pasado precolonial?

La exploración biográfica realizada nos ofrece una idea de la riqueza del material producido por estos subalternos y potencialmente existente en archivos, colecciones privadas y/o museos. En el caso de Zegarra debemos recordar que él describe sus cuadernos de Huallamarca como «diario de campo con sus respectivas ilustraciones» como también sucede en los casos de Pachacamac (1945, 1962-1964), Ancón (1945-1949, 1950-1956, 1961), Juliana y «de la universidad» (1950-1956), Catalina Huanca y Huaquerones (1957), San Juan de Pariachi (1957-1958) y Paramonga (1960) (Zegarra, 1983: 1-2), por lo cual cabría esperar que estos textos aún existan tal como sucede con los de Ancón (MNAAHP, Archivo Tello) y de Pachacamac (Museo de Sitio Pachacamac)18. Si nos remitimos únicamente al emblemático caso de las excavaciones del Museo de Antropología y Arqueología en Ancón, es un indicador de la historia de la arqueología nacional que luego de hacer tantas excavaciones y registrarlas, este material no haya sido sistemáticamente incorporado en la narrativa del pasado precolonial (ver Kaulicke, 1997: III). Hasta la actualidad este tipo de material constituye una especie de lastre de la disciplina, sin un procesamiento adecuado que permita su difusión e interpretación.

En el caso de los cuadernos de Zegarra sobre Huallamarca, pese a que la cantidad de material excavado es mucho menor que la de Ancón, estos documentos están llamando más la atención de los arqueólogos, especialmente por ser la referencia indispensable para comprender la ocupación precolonial tardía del sitio, y para articular la información sobre el valle del Rímac. Sin embargo, estos cuadernos también nos han servido como pista para aproximarnos a un tipo de personaje

18 En el Museo de Sitio de Puruchuco había cuadernos de Zegarra sobre Paramonga, Puruchuco y San Juan de Pariachi, entre otros. Algunas de sus notas sobre San Juan van en uno de los volúmenes sobre Huallamarca. 
clave en Arqueología cuyo papel en la producción de la narrativa sobre el pasado precolonial recién estamos comenzando a comprender.

\section{Agradecimientos}

En 2000, cuando era director del Museo de Sitio de Huallamarca tuve acceso a los cuadernos de campo de Jorge Zegarra sobre ese sitio arqueológico depositados en el Museo de Sitio de Puruchuco. El 2002 obtuve una beca de la Cooperación Técnica Belga (CTB) para realizar mi proyecto sobre los cuadernos de Zegarra con la cordial asesoría de Peter Eeckhout, mientras llevaba cursos durante un semestre en la Universidad Libre de Bruselas. El resultado final fue un reporte sobre los cuadernos de campo de Zegarra (Ramón, 2003). Agradezco a Lieve Delanoy por animarme a postular a esa estupenda beca. Por el acceso a los cuadernos de campo de Huallamarca y a la colección de artefactos asociados agradezco a Luis Felipe Villacorta y a Teresa Verástegui, ex directores del Museo de Sitio de Puruchuco. Por el acceso a los cuadernos de campo de Pachacamac, a Denise Pozzi Escott, directora del Museo de Sitio de Pachacamac. A Elizabeth López, María Eugenia Huayanca y Alex Ortegal en la Unidad de Archivo del Museo Nacional de Arqueología, Antropología e Historia del Perú. Daniel Dávila ha sido fundamental durante todo este proceso, él trabajó en los depósitos del Museo de Sitio de Puruchuco identificando y dibujando las piezas excavadas por Zegarra y me contactó con la familia Zegarra. Este texto existe gracias a la cortesía y la colaboración de doña Isabel Loza y don Óscar Zegarra. Óscar Zegarra no solo respondió a todas mis preguntas sobre su recordado hermano, sino que preparó un valioso dossier documental, fundamental para mis investigaciones. A Gustavo Emé, Martín Mac Kay y Víctor Paredes por compartir sus conocimientos sobre el tema. A los dos revisores anónimos y, especialmente, María Eugenia Yllia por las observaciones y recomendaciones. Todas las fotos de material de archivos y periódicos aquí incluidas fueron tomadas por el autor del presente artículo.

\section{Referencias citadas}

\section{Fuentes primarias}

Archivo Tello, Archivo Histórico del Museo Nacional de Arqueología, Antropología e Historia

Diario de los Trabajos Arqueológicos en Ancón (5 agosto-29 noviembre 1946), AT-0262001 Tomo IX

Diario de Trabajos Arqueológicos en Ancón (31 enero-14 febrero 1949), AT-051-2001 Tomo XXVII

\section{Archivo Óscar Zegarra}

ZEGARRA, J., 1947 - Informe anual de mis trabajos realizados durante el año de 1947: 1 p. ZEGARRA, J., 1949 - Informe anual de los trabajos realizados por el empleado Jorge Zegarrra, durante el año de 1949 (Memoria): 1 p. [incompleto, solo consigna actividades de enero a agosto]

ZEGARRA, J., 1983 - Curriculum Vitae, 2 pp. 


\section{Museo de Sitio Pachacamac}

ZEGARRA, J., 1961-1962 - Cuaderno 2. Del 15 de Agosto de 1961 al 20 de Abril de 1962. ZEGARRA, J., 1962-1963 - Cuaderno 3. Del 21 de Abril de 1962 al 13 de Enero de 1963. ZEGARRA, J., 1961-1962 - Cuaderno 4. Del 14 de Enero de 1963 al 24 de Enero de 1964.

\section{Museo de Sitio Puruchuco}

ZEGARRA, J., 1958a - Trabajos de restauración limpieza y rescate de especímenes arqueológicos en la H.P.A. o Huallamarca. Dirigida por: dr. Jiménez Borja. Diario de: (.... ) Del 14 de marzo al 23 de junio 1958 (Tomo I) [Manuscrito] [Código: 0006].

ZEGARRA, J., 1958b - Trabajos de restauración limpieza y rescate de especímenes arqueológicos en la H.P.A. o Huallamarca. Dirigida por Jiménez Borja. Diario de: (.....) Del 24 de junio al 16 de octubre 1958 (Tomo II) [Manuscrito] [Código: 0007].

ZEGARRA, J., 1958c - Trabajos de restauración limpieza y rescate de especímenes arqueológicos en la H.P.A. o Huallamarca. Dirigida por Jiménez Borja. Diario de : (.....) Del 17 de octubre 1958 al 29 de junio 1961 (Tomo III) [Manuscrito] [Código: 0008].

ZEGARRA, J., 1958d - Continuación de los trabajos de restauración de H.P.A. [Mecanografiado] [Código: 0040].

ZEGARRA, J., 1960 - Diario de los trabajos de limpieza en la HPA o Huallamarca. Trabajos controlados por el sr. René Candela. Del 8 agosto al 30 agosto de 1960 [Manuscrito] [Código: 0010].

ZEGARRA, J. \& F. IRIARTE, 1958a - Trabajos de Limpieza en H.P.A. (Huallamarca) del 10 febrero de 1958 al 8 diciembre 1958 [Manuscrito] [Código: 0009].

ZEGARRA, J. \& IRIARTE, F., 1958b - Huaca "Pan de Azúcar" Huallamarca. Diario de campo [Mecanografiado] [Código: 0035].

\section{Fuentes secundarias}

ÁNGELES FALCÓN, R., 2011 - Cerámica Inca en Pachacamac, 79 pp; Lima: Ministerio de Cultura.

BUSE de la GUERRA, H., 1962 - Perú 10,000 años, 273 pp.; Lima: P. L. Villanueva.

BUSE de la GUERRA, H., 1965 - Introducción al Perú, 393 pp.; Lima: Imprenta del Colegio Militar Leoncio Prado.

CÁRDENAS MARTíN, M., 1993 - El Perú prehispánico visto por Raimondi. Boletín del Instituto Riva Agüero, 20:129-138.

CARLSON, U., 2000 - Comentarios sobre las ilustraciones seleccionadas. In: El inicio de la arqueología científica en el Perú: Reiss y Stübel en Ancón. Exposición de litografías de 1875 publicadas en "The Necropolis of Ancon in Peru": 24; Lima: Museo de Arte.

CARRIÓN CACHOT, R., 1948 - La cultura Chavín. Dos nuevas colonias: Kuntur Wasi y Ancón. Revista del Museo Nacional de Antropología y Arqueología, 2 (1): 99-172.

CARRIÓN CACHOT, R., 1949a - Crónica de una visita a la Necrópolis de Ancón. El Comercio, 2 de marzo.

CARRIÓN CACHOT, R., 1949b - Importancia de la Necrópolis de Ancón. El Comercio, 3 de marzo.

CARRIÓN CACHOT, R.,1951 - Ancón. Elementos culturales de tres épocas hallados en la Necrópolis de Ancón: tercera exposición especial en homenaje al cuarto centenario 
Ilustrar el pasado precolonial andino: el caso de Jorge Zegarra Galdós

de la Universidad Nacional Mayor de San Marcos, 1551-1951, 20 pp; Lima: Museo Nacional de Antropología y Arqueología, Museo de Arqueología de la Universidad.

CORNEJO GUERRERO, M. A., 1998 - Sacerdotes andinos y rituales de sangre en el Tawantinsuyu. Boletín del Instituto Riva Agüero, 25: 187-198.

DÍAZ-ANDREU, M., 2013 - Últimas reflexiones y nuevas propuestas. In: Historia de la Arqueología en el Perú del siglo XX (H. Tantaleán \& C. Astuhuamán, eds.): 603-616; Lima: Instituto Francés de Estudios Andinos, Institute of Andean Research.

DOLORIER, C., 2013 - Cronología, organización social, especialización laboral y género definidos como productos del análisis de los contextos funerarios registrados en los diarios de campo de Huallamarca, años de 1958 y 1960; Lima: Universidad Nacional Mayor de San Marcos, Facultad de Ciencias Sociales. Tesis de Licenciatura en Arqueología.

DOLORIER, C. \& CASAS, L., 2008 - Caracterización de algunos estilos locales de la Costa Central a inicios del Intermedio Tardío. Arqueología y Sociedad, 19: 23-42.

DOLORIER, C. \& CASAS, L., 2009 - Caracterización del Estilo Tricolor Geométrico y Evaluación de Contactos con el Estilo Ychsma. Revista Chilena de Antropología, 20: 169-188.

DOLORIER, C. \& CASAS, L., 2014 - Mates de Huallamarca, iconografía y función: señores costeños, reciprocidad y símbolos de poder. Arqueología y Sociedad, 28: 177-198.

DOLORIER, C. \& CASAS, L., 2016 - Caracterización del estilo Hualla inciso punzonado del Ychsma Temprano. Arqueología y Sociedad, 31: 223-44.

ECHEVARRÍA LÓPEZ, G. T., 2012 - Julio C. Tello y la Ilustración Arqueológica Peruana. Arqueología y Sociedad, 24: 107-136.

EMÉ LEYVA, G. 2017 - Los ilustradores de Julio C. Tello: la influencia del indigenismo telúrico-arqueológico en su obra, 1935-1965; Lima: Pontificia Universidad Católica del Perú, Escuela de Posgrado. Tesis de Maestría en Historia del Arte.

EL COMERCIO, 1958a - Puruchuco recobró la pureza y dignitdad de su primitiva arquitectura, 3 de marzo 1958.

EL COMERCIO, 1958b - La huaca mas antigua de Lima deja ver sus secretos de hace 17 siglos, 1 de diciembre 1958.

EL COMERCIO, 1958c - Abren muestra de objetos de la época precolombina, 2 de diciembre 1958.

EL COMERCIO, 1971 - Comienzan a rehabilitar la huaca "Santa Catalina", 6 de marzo 1971.

EXPRESO, 1964 - Arqueólogo salva "Templo del Sol", 17 de febrero 1964.

FRANCO JORDÁN, R., 2004 - Poder religioso, crisis y prosperidad en Pachacamac: del Horizonte Medio al Intermedio Tardío. Bulletin de I'Institut Français d'Études Andines, 33 (3): 465-506.

GÄNGER, S., 2014 - Relics of the past. The Collecting and Study of Pre-Columbian Antiquities in Peru and Chile, 1837-1911, 328 pp.; Oxford: Oxford University Press.

GHERSI, H. \& ZEGARRA., J., 1971-1972 (Ms.) - Segundo informe sobre los trabajos realizados en la Huaca de Santa Catalina ubicada en el parque Fernando Carbajal Segura en el distrito de La Victoria. 18 de octubre de 1971-18 de marzo de 1972, 33 pp.; Lima: Municipalidad de La Victoria.

GUERRERO, D., 2004 - Cronología cerámica y patrones funerarios del valle del Rímac: una aproximación a los periodos tardíos. In: Puruchuco y la sociedad de Lima: un homenaje a Arturo Jiménez Borja (L. F. Villacorta Ostolaza, ed.): 157-177; Lima: Concytec. 
HAAS, R., 1986 - Keramikfunde aus Ancón, Perú. Die Tonobjekte der Sammlung Reiss und Stübel im Museum für Volkerdunde Berlin, 404 pp.; Berlin: Gebr. Mann Verlag.

HERNÁNDEZ, R., 2012 - Las piedras suplican auxilio. Arqueólogos, huaqueros y autoridades locales en Chavín de Huántar (1870-1945). Histórica, 36 (2):113-138.

HORKHEIMER, H., 1962 - Arqueología del valle de Chancay, catálogo de la exposición del Museo de Arte de Lima (17-30 de agosto de 1962), 12 pp.; Lima: Embajada de la República Federal de Alemania.

HUAPAYA, C., 1948 - Nuevo tipo de tumba descubierto en las necrópolis de Ancón. Revista del Museo Nacional de Antropología y Arqueología, 2 (1): 93-98.

JIMENEZ BORJA, A., 1958 - Primeros pobladores de San Isidro, El Comercio 16 de noviembre, Suplemento Dominical.

KAULICKE, P., 1997 - Contextos funerarios de Ancón. Esbozo de una síntesis analítica, 123 pp. Lima: Pontificia Universidad Católica del Perú-Fondo Editorial.

LA INDUSTRIA 1968 - Encontraron restos mochicas: Huanchaco, 3 de febrero 1968.

LA PRENSA, 1958 - En Fardo Funerario de 80 Kilos de Lienzos Antropólogos Sólo Hallan Un Pie Momificado, 11 de diciembre 1958.

LA PRENSA, 1971 - Notas de Distritos, 8 de marzo 1971.

LA TRIBUNA, 1958 - Huaca Pan de Azúcar será convertida en un Museo de Arqueología, en San Isidro, 2 de diciembre 1958.

MAC KAY FULLE, M. 1997 - Figurinas del valle del Rímac. Boletín del Instituto Riva Agüero, 24: 245-293.

MARTíNEZ, G., 1977 - Canto de Sirena, 164 pp. Lima: Mosca Azul.

MEJÍA, T., 2002a - Diario de Campo 1. Cuadernos de Investigación del Archivo Tello 3: 1377; Lima: Museo de Arqueología y Antropología.

MEJÍA, T., 2002b - Diario de Campo 2. Cuadernos de Investigación del Archivo Tello 3: 78132; Lima: Museo de Arqueología y Antropología.

MELGAR VÁSQUEZ, M., 2014 - El legado de Toribio Mejía Xesspe. Cultura, Ciencia y Tecnología. ASDOPEN-UNMSM, 5: 31-42.

MODONESI, M., 2012 - Subalternidad. In: Conceptos y Fenómenos Fundamentales de Nuestro Tiempo: 1-12; México: Universidad Nacional Autónoma de México.

http://conceptos.sociales.unam.mx/conceptos_final/497trabajo.pdf. Consultado 24 de febrero de 2018.

PILLSBURY, J. 2012 - Perspectives: Representing the Pre-Columbian Past. In: Past Presented. Archaeological Illustration and the Ancient Americas (J. Pillsbury ed.): 1-46; Washington D.C.: Dumbarton Oaks Research Library and Collection.

POOLE, D., 1997 - Vision, Race, and Modernity. A Visual Economy of the Andean Image World, 272 pp.; New Jersey: Princeteon University Press.

PRINGLE, H., 2012 - Portrait of the archaeologist as young artist. http://www. lastwordonnothing.com/2012/06/07/portrait-of-the-archaeologist-as-young-artist/. Consultado 24 de febrero de 2018.

RAGO, D., 2010 - La vida de Pedro Rojas Ponce. In: La llustración Arqueológica de Pedro Rojas Ponce (F. Torres \& A. Williams, eds.): 9-35; Lima: Instituto Cultural Peruano Norteamericano.

RAIMONDI, A., 1874 - El Perú. vol. 1, 444 pp.; Lima: Imprenta del Estado.

RAMÓN, G., 2003 - El material arqueológico de Huallamarca (Lima, Perú): análisis de los cuadernos de campo de Jorge Zegarra G. (1958 y 1960), 76 pp; [Informe final beca de la Cooperación Técnica Belga]. 
Ilustrar el pasado precolonial andino: el caso de Jorge Zegarra Galdós

RAMÓN JOFFRÉ, G., 2014 - El Neoperuano: arqueología, estilo nacional y paisaje urbano en Lima, 1910-1940, 119 pp.; Lima: Municipalidad de Lima Metropolitana, Sequilao Editores.

RAMÓN JOFFRÉ, G., 2017 a - Figurar la historia precolonial andina. In: Repensar el antiguo Perú: aportes desde la arqueología (R. Vega Centeno, ed.): 555-578; Lima: Instituto de Estudios Peruanos, Pontificia Universidad Católica del Perú.

RAMÓN JOFFRÉ, G., 2017b - Shaping precolonial concepts in the Andes: the ushnu for Llocllayhuancupa (Huarochirí, Lima). Latin American Antiquity, 28 (2): 288-307.

RAVINES SÁNCHEZ, R., 1977 - Prácticas funerarias en Ancón (primera parte). Revista del Museo Nacional, XLIII: 327-397.

RAVINES SÁNCHEZ, R., 1981 - Prácticas funerarias en Ancón (segunda parte). Revista del Museo Nacional, XLV: 89-166.

REISS, W. \& STÜBEL, A., 1880-1887 - The Necropolis of Ancon in Perú: A Contribution to Our Knowledge of the Culture and Industries of the Empire of the Incas, Being the Result of Excavations Made on the Spot, 3 vols.; Berlín: A. Asher \& Co.

RIVERO, M. de \& TSCHUDI, J. D., 1851 - Antigüedades Peruanas. 2 vols.; Viena: Imprenta Imperial de la Corte del Estado.

SENADO, 1953 - Las ruinas arqueológicas del Perú: el Senado de la República interviene en su defensa y conservación, 146 pp.; Lima: El Cóndor. Disponible en: https:// pucp.ent.sirsi.net/client/es_ES/campus/search/results?qu $=$ Las + ruinas + arqueol $\% \mathrm{C}$ 3\%B3gicas+del +Per\%C3\%BA\&te $=\&$ rt $=$ false $\% 7 C \% 7 C \% 7 C T I T L E \% 7 C \% 7 C \% 7 C T \%$ C3\%ADtulo

TANTALEÁN, H., 2014 - Peruvian Archaeology. A critical history, 215 pp.; Walnut Creek, California: Left Coast Press.

TANTALEÁN, H. \& ASTUHUAMÁN, C. (eds.), 2013 - Historia de la arqueología en el Perú del siglo XX, 627 pp.; Lima: Instituto Francés de Estudios Andinos/Institute of Andean Research.

TÉLLEZ CABREJOS, S., 2003 - Cirilo Huapaya y la investigación arqueológica. Boletín del Instituto Riva Agüero, 30: 435-459.

TELLO, J., 1999 [1929] - La huaca de Santa Beatriz. Cuadernos de Investigación del Archivo Tello, 1: 74-76.

TELLO, J., 1999 - Makat tampu. Cuadernos de Investigación del Archivo Tello, 1: 118-123.

TORRES, F. \& WILLIAMS, A. (eds.), 2010 - La ilustración arqueológica de Pedro Rojas Ponce, 99 pp.; Lima: Instituto Cultural Peruano Norteamericano.

TREVER, L., 2012 - The Uncanny Tombs in Martínez Compañon's Trujillo del Perú. In: Past Presented. Archaeological Illustration and the Ancient Americas (J. Pillsbury ed.): 107-140; Washington D.C.: Dumbarton Oaks Research Library and Collection.

UHLE, M., 1999 - Max Uhle (1856-1944) Pläne archäologischer Stätten im Andengebiet - Planos de sitios arqueológicos en el área andina, 199 pp.; Mainz: Philipp von Zabern.

VESCELIUS, G., 1966 - Review of Masks. Mummies and Magicians. Natural History, 75 (10): 64-66.

VILLACORTA, L. F., 2004 - Puruchuco, medio siglo después. In: Puruchco y la sociedad de Lima: Un homenaje a Arturo Jiménez Borja (L.-F. Villacorta, ed.):69-95; Lima: Concycet.

VILLACORTA, L. F., 2009 - Del asombro a la polémica: Arturo Jiménez y las momias del Perú. In: Centenario. Arturo Jiménez Borja, promotor cultural de Ate: 69-91; Lima: Municipalidad de Ate, Instituto Riva Agüero. 
VILLACORTA OSTOLAZA, L. F., 2012 - Antonio Raimondi, Archaeology, and National Discourse. Representation and Meanings of the Past in Nineteenth-Century Peru. In: Past Presented. Archaeological Illustration and the Ancient Americas (J. Pillsbury, ed.): 173-204; Washington D.C.: Dumbarton Oaks Research Library and Collection.

WAISBARD, R. \& WAISBARD, S., 1960 - La vie splendide des momies péruviennes, 251 pp.; París: René Julliard. 